H A R VAR D

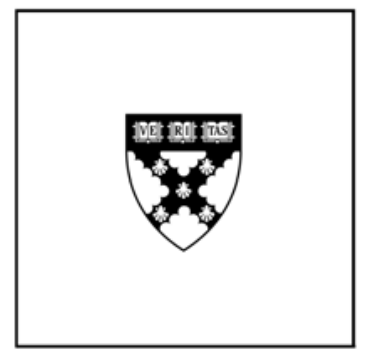

\title{
Management and the Financial Crisis (We have met the enemy and he is us ...)
}

William A. Sahlman

\section{Working Paper}

10-033 


\section{Management and the Financial Crisis (We have met the enemy and he is us ...)}

\section{William A. Sahlman, Harvard Business School}

The current model of corporate governance in the United States and abroad is badly broken and has been for many years. The financial crisis has revealed the degree to which there are problems. Neither managers nor boards of directors foresaw or prevented the massive value destruction that took place at companies like AIG, Bear Stearns, Fannie Mae, General Motors or General Electric. Nor did external private monitors like the media, securities analysts, credit analysts or ratings agencies raise sufficient warnings about building dangers. Certainly, public agencies like the Federal Reserve, FDIC and the Securities and Exchange Commission did little to preclude the financial conflagration.

The assertion that systemic failures of corporate governance caused the economic crisis is perhaps controversial. Some argue that lack of adequate regulation combined with excessive corporate greed was sufficient to cause the problems. If regulation had been more stringent, or executives less greedy, the crisis would have been averted.

Yet, I wonder what corporate manager would with hindsight have wanted what has happened to happen. Everyone, including those who behaved unethically and those who were consumed by greed (some overlap), ended up getting battered. Surely, independent of the existence of a strong and competent regulatory regime, sensible actors would have self-policed. Even greedy executives would not have wanted to see their companies disappear or their net worths vaporize.

Given the nearly universal harm inflicted by the crisis, one has to wonder why managers and boards of directors engaged in such risky behaviors and failed to protect themselves, their companies, and any other constituencies, from employees to communities. Even if their only stated objective was to "maximize shareholder wealth," they failed beyond all reasonable measures.

So, what went wrong? What should managers have done to protect their company (and the world)? What should boards of directors have done? What should regulators have done? What should investors have done? An interesting and parallel question is: What could they have done?

I believe that there are ways to improve how our global economic system operates but there are no magic bullets. Every aspect of the system needs change from government accounting to corporate board roles and structure - and changes to any single element of the system will fail unless all elements are changed. The most important and most difficult changes are those required of corporate 


\section{Management and the Financial Crisis - William A. Sahlman}

managers. Managers bear a disproportionate share of the responsibility for what transpired and therefore for what must change.

Sadly, there seem to be few new lessons from this crisis. What happened recently has happened before though perhaps not at the same scale. There were some unique contextual factors that created and sustained a larger and more pervasive than average financial bubble, but the underlying managerial failures were no different than in previous episodes of financial excess. Managers made dangerous and foolish decisions, consumers and investors engaged in risky behavior, and regulators were ineffective. Greed played a role but the bigger problem was incompetence.

The world is in the middle of a difficult period of adjustment and reflection. Most of the attention seems to be devoted to changing regulatory structures and rules that affect corporate governance and the financial markets. The changes that result will do little to decrease the likelihood or magnitude of the next bubble-panic cycle. The root causes of such cycles are deep and unlikely to be addressed through public policy or other external means.

I assert that most of the problems evidenced so prominently during this financial crisis can be traced to failures in five related managerial systems inside each major private and public actor in the financial markets:

- Incentives - how risk and reward are shared; how people behave if they act in their own perceived best interests given the structure of pecuniary and non-pecuniary payoffs

- $\quad$ Control \& Information Technology - how limits are placed on behavior; how information is captured and shared; how risk and reward are measured and how those assessments affect tactics and strategy

- $\quad$ Accounting - how managers choose accounting policies; how managers measure economic profits \& losses, as distinct from GAAP profits and losses

- Human Capital - the process by which people with certain characteristics (skill, experience, networks, character, and attitude) are attracted and managed or encouraged to leave any organization

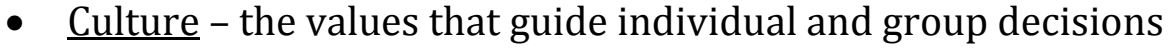

Enduring, successful companies have outstanding people (high skill and integrity); sensible accounting policies that mirror economic reality; excellent information, risk measurement and management systems; and, sensible incentives that balance personal and corporate risk and reward. These companies have a culture of doing the right thing that protects all major constituencies even when doing so doesn't maximize personal payoffs. Companies at risk have some combination of the opposite. 


\section{Management and the Financial Crisis - William A. Sahlman}

To see how the systems work individually and together, consider a group of securities traders at a Wall Street firm. Typically, traders are given strong incentives to make profitable trades - they get a big payoff if they do well. If they don't do well, they don't have to repay losses though they might be fired. In the U.S., getting fired does not necessarily preclude getting another job in the same industry.

Everyone knows that traders engage in a practice called doubling down; for example, if they put a trade on that goes against them, they want to double their position to make back the money they have lost and more. Or, they want to bet big on trades in which they have conviction.

Managers in charge of trading operations know that they have to pay close attention to the integrity, judgment, and skill levels of traders. They need to watch out for traders who take positions that are too large and too risky for the firm as a whole. They develop systems that track exposures by traders as well as aggregating the positions of all traders at the firm.

Finally, managers need to pay close attention to three related issues. They need to make sure they understand all aspects of a set of related trades so that they know the true net economic position and don't confuse profitability in one side with losses in the other. They also need to make sure that the reported values of securities in a trade are true market prices, not wishful thinking (or subterfuge) on the part of the traders. And, they need to distinguish between economic profits and accounting profits, which sometime differ by wide margins, particularly with regard to time horizons and risk.

In the past 20 years or so, there have been some remarkable examples of serious financial problems caused in firms whose managers failed to manage traders effectively. Examples include Societe Generale and Jerome Kerviel (loss of $\$ 7.2$ billion), Baring Securities and Nick Leeson ( $\$ 1.3$ billion), and Sumitomo and Yasuo Hamanaka ( $\$ 2.6$ billion). In each case an individual or a small group of individuals engaged in trading behavior that resulted in massive losses to the parent company. Typically, the individual could have earned a big bonus - in the millions of dollars - while the company lost billions of dollars, and, in some cases, failed completely.

That is the essential challenge in trading operations - attract highly skilled, honest traders, give them a share of the upside, watch them like a hawk to guard against risky and/or self-interested behavior, measure their risks and rewards accurately and continuously, and nurture a culture that protects and guides the organization. If managers mess up any element of the system they risk ruin, as has been shown many times.

This basic managerial challenge extends beyond financial trading operations. In many organizations, to illustrate, the sales staff has strong incentives to meet quotas on a quarterly or yearly basis. Some salesmen cross over the legal and 


\section{Management and the Financial Crisis - William A. Sahlman}

ethical boundary to meet or beat a quota, an activity that tends to occur in the last few days of the relevant period. They might get a customer to agree to buy a product while guaranteeing they can return it after the quarter. Or they promise future services that would disqualify the transaction as current revenue. Indeed, at the company level, senior managers have some of the same incentives as the sales force, given the pressure to meet earnings estimates at the end of the quarter and the high levels of management stock ownership that characterize many public firms.

That there are pressures to accelerate/overstate income or defer/understate expenses is not a blinding insight or necessarily a problem. Issues arise, however, if a firm has no internal controls that anticipate and deter such behaviors. Or, even more dangerous, if a company has a weak (or worse) ethical culture and no clear guidelines for how decisions are made independent of formal controls, then the pressures can be exacerbated. Such cultures tend to attract people prone to ethical and even legal lapses.

In studying the financial crisis as it unfolded over the past couple of years, it seems clear that many organizations suffered from a lethal combination of powerful, sometimes misguided incentives; inadequate control and risk management systems; misleading accounting; and, low quality human capital in terms of integrity and/or competence, all wrapped in a culture that failed to provide a sensible guide for managerial behavior. This assessment refers to financial services firms like Countrywide, AIG and Bear Stearns: it also applies to other actors like regulatory agencies, politicians, ratings agencies and probably to individual consumers.

One doesn't need to look far to find evidence that my assessment of the problem has merit. For example, the investment banking and wealth management behemoth UBS reported a shocking $\$ 18.7$ billion loss related to subprime mortgages for the year ended December 2007. That was followed by a first quarter loss of $\$ 19$ billion. In April of 2008 the company issued a special report to shareholders ${ }^{1}$ that diagnosed the causes of the loss. The report is remarkable in its candor. Basically, UBS revealed that they had fundamental failures in incentives, control systems, accounting decisions, and the people making decisions.

In the area of incentives, to illustrate, UBS discovered a few major flaws:

- Employees had strong incentives to engage in so-called carry trades in which they used UBS capital to invest in high-yielding mortgagebacked securities. UBS charged a very low cost of capital and did not vary that charge based on the riskiness of the assets being purchased.

- The fee structure at UBS provided special incentives to buy riskier securities. For example, traders received a fee 3 to 4 times as high when they bought risky CDOs (Collateralized Debt Obligations) than

\footnotetext{
1 UBS AG, Shareholder Report on UBS's Write-Downs, April 18, 2008.
} 


\section{Management and the Financial Crisis - William A. Sahlman}

when they bought safer ones. The accounting treatment allowed traders to book profits the moment the trade was executed with no clawback based on subsequent outcomes.

- UBS provided "insufficient incentives to protect the UBS franchise long-term." They gave lots of current cash compensation to individuals engaged in transactions that exposed the company to huge risks. They awarded bonuses that "were measured against gross revenue after personnel costs, with no formal account of the quality or sustainability of those earnings."

Broadly speaking, these incentives-related issues are classics: providing "strong" and "stronger" incentives to engage in risky behavior; having insufficient incentives to protect the company; and, measuring the wrong things with the wrong time horizon. These mistakes might not have been so costly had UBS had in place strong risk measurement and control systems and/or wise senior managers with responsibility and authority. In other parts of UBS's "mea culpa," management details failings in these areas as well.

The UBS report listed a staggering 75 different areas in which there were flawed decisions or processes that contributed to the company's losses in subprime mortgages. At the top level, management had developed a growth strategy that focused too much on growth in market share, revenues and profits and too little on risk. In each individual business unit, there were flaws in the measurement of risk, absent or weak constraints on the size of positions, bad accounting, and the aforementioned incentives issues. The people in charge of the related decisions either didn't have the requisite skill to understand the gathering risk, didn't have the authority to change decisions, or didn't have the right incentives to stop the looming train wreck. Moreover, the corporate financial decisions were not ultimately consonant with the risk of the asset decisions and in some cases exacerbated the overall riskiness of UBS. For example, the company held pools of highly rated securitized mortgage assets to provide liquidity in case of declines in asset values those values dropped precipitously and the liquidity of the assets also disappeared.

I have focused on UBS not because it was the worst managed firm but because it published a comprehensive report on its failings. Almost by definition many financial firms suffered from all or some of the same problems. A common theme, to illustrate, was that all the players in the markets relied heavily on ratings issued by firms like Moody's and Standard \& Poor's. Consider the following excerpt from the UBS report that describes the Market Risk Control (MRC) Unit:

MRC relied on the AAA rating of certain Subprime positions, although the CDOs were built from lower rated tranches of RMBS (Residential Mortgage Backed Securities). This appears to have been common across the industry. There is no indication that MRC sought to review the quality of existing portfolios as questions were being raised in relation to the Subprime sector more generally. A comprehensive analysis of the portfolios may have 


\section{Management and the Financial Crisis - William A. Sahlman}

indicated that the positions would not necessarily perform consistent with their ratings.

With hindsight, and probably with foresight, the ratings assigned by external ratings agencies to mortgage-backed securities were fatally flawed. These agencies had long been in the business of assessing the likelihood of default on single issuer corporate bonds. They ventured into the new and rapidly growing business of rating pools of asset-backed securities. Without getting too lost in the details, ratings were assigned based on a historical analysis of default rates on the underlying mortgages or other securities.

There were many technical issues associated with the way risks were assessed and ratings assigned, chief among them the implicit assumptions that house prices were highly unlikely to decline and that the correlation coefficient between house prices in different regions was low (i.e., if house prices declined in Miami, that didn't mean they would also decline in Phoenix). As we now know, house prices declined precipitously and everywhere, but especially in hot markets like Miami and Phoenix.

One issue at the ratings agencies was that they had evolved to an incentive structure that created the possibility of conflicts. Specifically, they were paid by the issuers of securities, not by the buyers or by the regulators. For a variety of reasons, there really were only two major ratings agencies - they competed intensely for the same customers. That is a system that may not result in the most accurate ratings but rather the ratings designed to curry favor with the customers in order to increase market share and profits. Competition was likely to exacerbate the problem.

The business of rating securitized assets was extraordinarily lucrative. Between 1997 and 2006, to illustrate, Moody's revenues from this source went up by a factor of nine, representing the largest revenue source for the company at the end of the period. The stock price went from under $\$ 15$ in 2001 to over $\$ 70$ in 2006. The company's operating margins in 2006 were $37 \%$.

Everybody working at S\&P and Moody's was no doubt trying to do the best job they could. The companies had internal policies designed to make sure that ratings were not influenced by a desire to gain business or market share. Moreover, nobody realized they were making dangerous assumptions about the possible course of housing prices. Yet, if you think about it, the explosion in revenues, profits and stock price at both firms certainly mitigated a desire to call a halt to the party.

That basic sentiment applied to almost everyone in the financial services business from roughly 2002 to 2006 . Everything that could go right was going right. Profits, stock prices, and compensation were all skyrocketing and no one was eager to see the financial boom end. No one ever votes for a boom to end or even a bubble to burst. 


\section{Management and the Financial Crisis - William A. Sahlman}

That many of the problems encountered during the financial crisis had roots in the housing markets is attributable to the economic and political attractiveness of that sector in the global economy. Politicians of all stripes are eager to promote home ownership and rising home prices. The housing industry food chain is large and economically significant. The industry is also rife with fundamental challenges in terms of the nexus of incentives, control systems, accounting, and human capital.

Consider two major financial institutions - Fannie Mae and Freddie Mac. Both are privately-owned but government-sponsored enterprises (GSE) chartered by Congress with a mission to "provide liquidity, stability and affordability to the U.S. housing and mortgage markets." They accomplish this goal by buying or guaranteeing mortgage securities in secondary markets. Their cost of capital is low because they have an implicit guarantee from the U.S. government.

These are remarkably large, economically significant organizations. By the end of 2006, they held or guaranteed over $\$ 5$ trillion worth of U.S. mortgages, representing almost half the market. One obvious potential issue is that both companies have an explicit goal of maximizing shareholder wealth. Senior managers are paid private market salaries and have substantial stock ownership. If large losses occur, the U.S. government is on the hook. If the companies do well, the executives make a mint. That amounts to privatizing reward and socializing risk, a classic example of heads I win, tails you lose.

A second issue at Fannie Mae and Freddie Mac relates to a stated objective of encouraging home ownership among disadvantaged groups and/or in economically challenged regions. Each year, both organizations are required to report progress on these dimensions. Politicians often berated management at Fannie Mae and Freddie Mac to be more aggressive in supporting the social goal of increasing home ownership among the disadvantaged: Congressman Barney Frank once famously encouraged both organizations to "roll the dice" in the name of affordable housing. ${ }^{2}$ Yet, it may or may not make management sense to buy or guarantee loans in such areas or to such groups in terms of balancing risk and reward. These may be bad bets.

One additional concern, true for many government agencies, is that the government does not charge an insurance premium for its implicit guarantee of GSE-issued debts that varies with the riskiness of the investment decisions being made. Moreover, the rate charged is not a market rate at all but one negotiated politically between regulatory agencies and the companies.

2 Wall Street Journal, October 2, 2008, "What They Said About Fan and Fred" (http://online.ws).com/article/SB122290574391296381.html, accessed September $8,2009)$. 


\section{Management and the Financial Crisis - William A. Sahlman}

Putting these three systems together creates a volatile mix. The government insures a set of activities but doesn't charge the right cost for the insurance and allows the companies to be highly leveraged. Politicians press for possibly risky loans, ironically increasing the economic cost of the guarantee. Private managers get to place bets with high potential personal payoffs and government guarantees. Frankly, it is not surprising that these organizations got into trouble when housing markets began to falter. Effectively, they are set up to thrive in rising markets and to fail miserably in declining ones.

Similar dynamics have always existed in markets in which the government bears part or all of the risk of certain private activities. Some would argue, I among them, that the Savings \& Loan crisis of the late 1980s reflected a toxic mixture of increased government guarantees of deposits, de-regulation of the industry, private ownership of companies, and a dramatic increase in the riskiness of investment decisions without a commensurate increase in insurance premiums required by the government. Though it seemed that the S\&L crisis, estimated to have cost the government almost $\$ 500$ billion, occurred in a relatively short period of time, the reality was that the financial hit should have been obvious years before when the perverse incentives were first put in place. The true budget deficit of the U.S. during the period leading up the actual crisis was higher than the reported deficit by an amount equal to the understated cost of insuring deposits.

Without dwelling too long on flaws in government policy, it is instructive to note that many current economic challenges can be directly related to a consistent pattern of understating the future consequences of current decisions, particularly those related to guarantees. Such guarantees are seemingly free for politicians to offer. I think of them as the "cocaine" of government - addictive and potentially fatal. Consider such prime examples as the Pension Benefit Guarantee Corporation, Medicare and Social Security. These are excellent examples of a system with strong individual and group incentives to provide voter benefits, poor risk assessment tools, terrible accounting, and individuals who are unable or unwilling to figure out the economic consequences of their decisions. These activities are all admirable from a social perspective - who can argue against protecting people's retirement security or health? - but, they are all fatally flawed because they didn't ever reflect the true economic costs and consequences of enactment.

One final piece of the puzzle in explaining the financial crisis concerns the competitive context in which companies (and other players) operate. To illustrate, when managers have strong incentives to grow profits or gain market share in highly competitive industries, they often become more aggressive in areas like pricing and product innovation. Otherwise they lose market share and suffer worse relative performance, at least in the short run. Or, when the economy is booming domestically and globally, the choices managers make may be very different than in the opposite circumstances. 


\section{Management and the Financial Crisis - William A. Sahlman}

Competitive pressures can result in a classic "race to the bottom" in standards. Imagine that you were a player in the mortgage business when the market was booming. There were lots of companies eager to attract business at each stage of the value chain - from the initial household borrowing decision to the securitization process at the end.

At any given firm the only way you could gain market share, or stay even, was to offer a compelling product to customers (and to employees). Unfortunately, in the mortgage business, the path of least resistance was to lower the standards for granting a loan and/or come up with unique pricing schemes like offering low introductory rates. In a hotly competitive business, the marginal price is often set by the lowest common denominator - the firm with the lowest quality, lowest integrity and most aggressive people; the weakest control systems; and, the most aggressive accounting systems. That is exactly what happened in the mortgage industry from 2001 to 2006, as well as in a wide range of other areas like high yield lending. Consider the following table that describes the rise of the subprime mortgage business during that period: ${ }^{3}$

\begin{tabular}{|l|r|r|}
\hline Year & 2001 & 2006 \\
\hline Subprime Mortgage Issuance & $\$ 180$ billion & $\$ 600$ billion \\
\hline Subprime/Total New Mortgages & $7 \%$ & $20 \%$ \\
\hline Average Loan-to-Value Ratio (LTV) & $74 \%$ & $84 \%$ \\
\hline \% Loans at 100\% of Assessed Value & $1 \%$ & $17 \%$ \\
\hline \% Loans with Limited Documentation & $33 \%$ & $63 \%$ \\
\hline \% Loans 100\% LTV \& Limited Documentation & $<1 \%$ & $11 \%$ \\
\hline
\end{tabular}

The race to the bottom in standards is clear from the aggregate data: it is even clearer in studying the activities of individual players during the boom. At Countrywide Financial, one of the largest mortgage lenders in the U.S., management had a strategy variously called the "matching strategy" or the "supermarket strategy." 4 Briefly, the company committed to "offering any product and/or underwriting guideline available from at least one 'competitor,' which included subprime lenders." This policy led to dramatic - and ultimately fatal - increases in the proportion of subprime loans, including an increase in subprime "Pay-Option ARM" loans. The latter category, representing over 20\% of the company's 2006 loan originations, were particularly risky because borrowers often had low credit scores, the loan-to-value ratios were high, and the likelihood of default significantly higher. Ultimately, Countrywide ran into severe financial difficulties and was purchased by

3 These data come from Whitney Tilson and Glenn Tongue, More Mortgage Meltdown, Wiley, New York, 2009, pp. 8-13.

4 This account is drawn from an SEC complaint against three executives from Countrywide on June 4, 2009 (see

http://www.sec.gov/litigation/litreleases/2009/lr21068a.htm, accessed 10/27/09). 


\section{Management and the Financial Crisis - William A. Sahlman}

Bank of America. In turn, that firm was almost destroyed by the toxic residue from buying Countrywide.

The "race to the bottom" in standards for lending characterized the mortgage business for sure. It also occurred in loans for leveraged buyouts. From 2002 to 2006-7, there was a dramatic shift in terms for such loans. At the beginning of the period, private equity firms paid just over six times EBITDA for companies and leveraged them at four times EBITDA. By the end of the period, those ratios had risen to eleven and seven, respectively. Moreover, the early loans had covenants that gave the lender certain rights in the event of a default. By the end, many loans were covenant-light, or even had no covenants.

Such races have one common element that warrants mention. You might imagine that markets would equilibrate before standards deteriorated to dangerous levels. In many of these markets, however, there is an illusory success factor. For example, in the market for leveraged buyouts, the equity and debt investors who bought early (e.g., 2002) ended up doing well. If you invested when valuations were low, used lots of low cost leverage, and sold when valuations went up, you reported very high rates of return. That, in turn, attracted even more money. That drove up prices, which drove returns even higher and gave investors the inevitably incorrect view that returns were high and risks low. Sadly, the converse is also true - if you buy on a leveraged basis when valuations are high and sell when they are low, you get massacred. Low returns drive money out of a sector, lowering the valuations of buyout candidates, further lowering rates of return. You get the picture.

Similarly, in the early days of the housing boom, mortgage providers, packagers and investors all made great money. As returns rose, more investors allocated capital to the sector, feeding an increase in the demand for houses. That, in turn, made the perceived risks lower. Loans made at high house loan-to-value ratios ended up with more manageable ratios as house values escalated. It never occurred to anyone that housing prices would ever do anything but go up. Indeed, the models used by S\&P and Moody's to rate housing related securities did not work - they blew up in a mathematical sense - if housing prices declined.

Few executives seem able to resist participating in these kinds of markets. Chuck Prince, CEO of CitiGroup, acknowledged in 2007 that the market for leveraged loans was overheated, but remarked, "When the music stops, in terms of liquidity, things will be complicated. But as long as the music is playing, you've got to get up and dance. We're still dancing." 5

The mortgage business also illustrates another perplexing issue in management systems particularly in the context of the current financial crisis. Historically, borrowers would get mortgages from the local bank or S\&L. They

5 Michiyo Nakamoto and David Wighton, "Citigroup chief stays bullish on buy-outs," The Financial Times, July 92007. 


\section{Management and the Financial Crisis - William A. Sahlman}

would know the banker and the banker would know them. The financial institution would hold the loan until it was repaid and they would monitor the financial health of the borrower until that point. That system changed as the securitization market evolved. Lenders were able to repackage loans and sell them as part of larger securities bundles. They got compensation immediately. That separated the borrower from the lender and led to some serious challenges. Notably, the original lender passed the risk onto the next owner while collecting income on a current basis in the form of fees and a profit on the sale of the securities. They were far less concerned about making good loans than they might have been had they retained a significant ownership interest or had some ongoing liability if the loan went bad.

Now it turns out that many firms (though not necessarily the individuals involved) that packaged mortgage securities in securitized pools did retain some economic interest in the pool even when they booked the transaction as a sale. It's a complicated story that reveals another challenge with accounting. Without getting too technical, many firms that packaged mortgage securities had an implicit commitment to make good on certain mortgages in the pool if they went "bad" early. As often happens in accounting, the firms involved had to estimate the implicit liability and hold capital in reserve to meet the obligation. With hindsight, and probably with foresight, the estimated liabilities were understated by wide margins. Stated differently, profits were overstated and too little capital was set aside.

Throughout the financial system, a recurring theme turned out to be how firms chose to book profits and losses as well as assets and liabilities. When executives receive compensation based on accounting profits, they have strong incentives to maximize accounting profits. More often than not, executives choose liberal interpretations of accounting rules in determining the profit figures on which their bonuses are based.

To illustrate, when Lone Star Partners, a well-regarded investor in distressed debt, went to Merrill Lynch in the July of 2008 to bid on a pool of mortgage-backed securities that Merrill held on its books, they discovered that the securities had declined dramatically in value from Merrill's cost. Basically, Lone Star won the right to buy $\$ 30.6$ billion in securities for $\$ 6.7$ billion, with Merrill supplying $75 \%$ of the financing for the transaction on very attractive terms. That's a considerable loss for so-called super-senior tranches of mortgage pools.

When Lone Star's founder John Grayken asked why Merrill had ended up with such a big position (the total exposure was $\$ 44$ billion or so), he learned several interesting things. First, Merrill booked a profit on selling the securitized pool at a price higher than the cost of assembling the pool. Second, Merrill sold the securities to a Merrill-controlled Qualified Special Purpose Entity (QSPE) that could be levered 20 to 1 and whose assets and liabilities did not have to be consolidated on the parent company's balance sheet. Because the QSPE borrowed in the shortterm market at low rates and because the yield curve was positive, Merrill could book additional profits on the spread between the rates paid on the mortgages and 


\section{Management and the Financial Crisis - William A. Sahlman}

the cost of funds. Basically, Merrill sold the securities at a profit to itself and took additional profits on the spread between the interest rate on the pool and the shortterm cost of funds. For the executives involved, profits, and therefore bonuses, were higher. For Merrill, reported profits were higher, the balance sheet was not compromised, and the stock price went up.

This is an example of a situation in which managers with strong incentives made decisions about how to account for certain transactions. In many businesses, it is easy to figure out the profitability of a transaction. That is not necessarily so easy in a business like packaging and selling pools of mortgage securities. Many assumptions have to be made and there are complicated contingent payoffs and liabilities. Managers are certainly tempted to use the most liberal treatments when they have cash or stock bonuses based on short-term profitability.

No assessment of the root causes of the financial crisis would be complete without consideration of the financial services giant, AIG. ${ }^{6}$ In the fall of 2008, the possible failure of AIG triggered a wide range of government responses that have forever changed the global financial landscape. AIG was a widely respected company that focused on insurance. In mid-2007, AIG's total market capitalization was almost $\$ 200$ billion. By October 2008, the total market value of the company was under $\$ 10$ billion and the government had invested almost $\$ 100$ billion in saving the company.

Real-time history is always complicated but a clear issue at AIG was that a small group of employees (under 400) in its Financial Products group (FPG) wrote a large amount (over $\$ 500$ billion) of insurance on corporate bonds and pools of asset-backed securities, including pools of mortgage-backed securities. Because AIG had impeccable credit, and because few people thought there was risk in any of these securities, FPG was able to write insurance with no up-front collateral requirements. Thus, any profits represented a very high return on capital (think infinite).

FPG was originally formed in 1987 and had been consistently profitable for AIG over a long period of time. Early on, FPG's senior executives had worked out a highly lucrative deal with AIG that enabled them to share directly in the profits they generated. They could leverage AIG's strong balance sheet and keep over $30 \%$ of the profits. As a result, management had a very strong incentive to grow the business. That incentive had worked well for many years under two successive managers, but ran into to trouble beginning in 2002 when a new manager took charge.

${ }^{6}$ Michael Lewis provides an insightful treatment of events at AIG in "The Man Who Crashed the World," Vanity Fair, August 2009.

(http://www.vanityfair.com/politics/features/2009/08/aig200908, accessed September 9, 2009). 


\section{Management and the Financial Crisis - William A. Sahlman}

The new group leader - Joe Casanno - had a different leadership style. He was very hard on employees - the word used was "dictatorship" - but generous with compensation with everyone, even those he castigated. He was driven to succeed. He was also perceived to be technically weaker than his predecessors in the sense that he was not necessarily able to understand the mathematical complexities of the insurance product his unit sold.

I stress the transition in management to point out the obvious fact that every company makes periodic risky bets about who should lead an organization. Indeed, AIG had changed CEOs in 2005 when long-time executive Hank Greenberg was forced out of the company. In some cases, those bets don't work. In a subset of those bets, the individual chosen can put the entire organization at risk.

Under Joe Cassanno's leadership, FPG ended up insuring a large number of mortgage-backed securities just as the riskiness of those securities increased. AIG had created very strong incentives for Cassanno and his team and was heavily dependent on the quality of their decisions, particularly because FPG could put AIG's balance sheet at risk. This was, parenthetically, the same basic compensation system as that described earlier for UBS, Fannie Mae and Freddie Mac: individuals could use OPM (Other People's Money) to make subsidized bets in which they kept the upside and another party held the risk.

The team at FPG no doubt believed that the insurance contracts they were selling represented sensible risks. Yet, they had created a structure that was highly leveraged in several ways. First, though FPG was not required to post up front collateral to underwrite its insurance in the beginning, the contracts called for significant collateral in the event the underlying securities deteriorated in value and an even larger increase if AIG lost its AAA credit rating. Second, the group went from insuring pools of higher quality prime mortgages to insuring pools of subprime mortgages. The latter pools were typically given to people with lower credit scores at higher loan-to-value ratios and less, or no, documentation. Though AIG might have had the same leverage, the securities they were underwriting were much more highly leveraged and were written at a time when house prices had zoomed (a technical term appropriate when house prices rise by three standard deviations above the historical trend). Finally, it turned out that there were other parts of AIG that had bet heavily on the same kinds of mortgage-backed securities. When house prices began to fall, AIG suffered in many ways, with the cash and value exposure at FPG being the major pain point.

In 2007 and up until September 2008, the counterparties to FPG's insurance business - the organizations that had purchased insurance against a decline in value of various debt securities - began to demand additional collateral from FPG to protect their contracts. On September 15, 2008, AIG's credit rating was lowered from AAA to AA, causing a $\$ 32$ billion single-day increase in required collateral. By definition, concern about the financial impact on AIG caused concern about AIG's counterparties that had relied on AIG's insurance to protect them against loss. 


\section{Management and the Financial Crisis - William A. Sahlman}

Ultimately, fears about a major financial panic precipitated by the collapse of AIG forced the government to step in and effectively insure the insurance.

Joe Cassanno and his team had not only put AIG at risk by insuring risky pools of mortgage-backed securities, they had also put the country at risk. Like $99 \%$ of the other managers at financial services firms, however, FPG's managers did not ever consider that there was any chance that AIG would lose money, much less that the entire global financial system would get in trouble. As late as August 2007, Cassanno specifically said, "It is hard for us, without being flippant, to even see a scenario within any kind of realm of reason that would see us losing $\$ 1$ on any of these transactions." Moreover, FPG had actually started to withdraw from the market for insuring mortgage-backed securities as early as 2005. By that point, however, the damage had been done, particularly given the additional exposure to mortgages in other parts of AIG and continued utilization of AIG's balance sheet to underwrite risky financial derivative contracts. The company was vulnerable to a crisis in confidence, which is what ultimately caused its demise as a privately owned enterprise.

The AIG - FPG saga is revealing in a number of ways. First, there was no grand conspiracy to bring down the global financial system. The individuals involved made mistakes. Perhaps they made those mistakes because they were incompetent, perhaps because they were blinded by money; at this point, the distinction is moot for all those who lost money as a result of AIG's failure. That includes the executives who made the mistakes, many of who lost fortunes as AIG's stock price sank precipitously.

The obvious question is: Who allowed AIG to get so far out on a financial limb? The answer is complicated to be sure but there are some clear lines of responsibility. The first line of defense for any company is management. The CEO and executive team were responsible for the financial health of the company and failed to appreciate the joint riskiness of decisions made in a number of business units. The individuals running specific business units didn't make sensible decisions.

Nor did AIG's board of directors call a halt to the risky practices that contributed to the demise of the company. At quite a few points before its collapse, management and the board could have taken steps to de-risk the company by lowering overall exposure to the housing industry and/or by raising additional permanent capital. Instead, AIG's leaders insisted that the company was adequately capitalized and faced limited risk even after housing prices started to fall in 2006. The company had even engaged in a share-buyback program that did not end until 2007.

One challenge at AIG was the staggering scale and complexity of the company. The company's assets at the end of 2007 exceeded $\$ 1$ trillion with stockholders' equity of just under $\$ 100$ billion. The company had 116,000 


\section{Management and the Financial Crisis - William A. Sahlman}

employees. AIG operated in many different businesses on a global basis ranging from a ski resort in Vermont to life insurance in Japan. The company had written insurance on everything from typhoons to asbestos claims to the value of pools of subprime mortgages. AIG's $200710-\mathrm{K}$ contained 231 pages. The footnotes to the financial statements ran 67 pages; and, those footnotes are remarkably complex.

Imagine that you were a director of AIG at the point they issued their 2007 $10-\mathrm{K}$ and annual report. How much time and skill would have been required to read the report and fully digest its contents? How much time would have been required to meet and assess the people - like Joe Cassanno - to determine if they were up to the task?

In 1990 I wrote an article titled "Why Sane People Shouldn't Serve on Public Boards." ${ }^{7}$ I argued that there were substantial risks associated with being a director primarily in terms of reputation and loss of control over time. Though director compensation at the time was rising, I did not believe that the upside offset the downside. I also believed that directors would find it very difficult to do their duty in any moderately large and complex publicly traded company.

If I was correct in my assessment in 1990 the imbalance between risk and reward in more recent years has gotten worse, not better, as illustrated by considering a directorship at AIG. According to the company's 2007 proxy statement each director received a retainer of $\$ 75,000$ per year, a $\$ 1,500$ per meeting fee, and $\$ 160,000$ in common stock equivalents. There were additional payments for committee chairs (e.g., $\$ 25,000$ per year for the chair of the Audit Committee) so the basic annual pre-tax compensation per director was slightly over $\$ 260,000$. The company had 13 directors with an average age of almost 64 . Quite a few of the directors had active, full-time positions in other companies, and many were on other boards of directors.

The directors at AIG presided over one of the greatest financial failures in history. Considering that their stock grants became essentially worthless, they worked for an amount likely to be "rounding error" on their personal income statements and balance sheets. Like the directors of Enron and WorldCom, they will forever be associated with a failure and they will spend countless hours in legal depositions. They may be exposed to personal financial risk if they are found to have violated their duty of care or loyalty.

I believe that the likelihood that the directors of AIG - or those at GE, CitiGroup, Morgan Stanley, etc. - could have understood and anticipated the problems at their company was essentially zero. Even if each director became a true financial expert, knowledgeable about insurance, derivatives, valuation and accounting, they could not possibly have spent enough time to figure out what was

7 William A. Sahlman, "Why Sane People Shouldn't Serve on Public Boards," Harvard Business Review 68, no. 3, May - June 1990. 


\section{Management and the Financial Crisis - William A. Sahlman}

going on. Almost by definition, the directors of such complex organizations depend on management to provide and interpret information and are unlikely to have the ability to do their duty.

In looking at the boards of the various players in the financial markets, there were some highly skilled people in every firm. Robert Rubin, a director at CitiGroup, was formerly a co-chairman of Goldman Sachs and later Secretary of the Treasury. He helped create Goldman's systems and culture but was not able to bring the same discipline to CitiGroup. Martin Feldstein was a director at AIG. Feldstein is a distinguished professor at Harvard and a former Chairman of the Council of Economic Advisors. Henry Kaufman was a director at Lehman Brothers and a former Salomon Brothers executive with a distinguished history of calling trends in bond markets. In short, every firm, good and bad, had talented, high integrity people on their board.

I believe that the typical structure of board work creates additional challenges beyond the issues of scale and complexity. For example, boards typically have an audit committee and a compensation committee. The basic premise of this article is that you can't separate those two functions. Even the work of such committees is flawed. Compensation committees spend more time on relative levels of compensation of senior managers than on understanding the nature of incentives throughout an organization, how those incentives drive accounting choices, and what controls are needed to modulate behavior. At AIG, there was also a risk management committee but it is hard to see how that committee can function without deep understanding and involvement in the other two committees.

You might argue that external auditors can and should play an important role in helping organizations manage risk and reward. That is certainly true but auditors focus on the accuracy of the numbers, the accounting policies, and the processes surrounding financial accounting and controls. Auditors are not typically in a position to assess the financial risks and rewards to which a company is exposed because of its strategy. AIG's audit firm did identify weaknesses in internal controls at FPG in particular during 2007 as described in the company's 10-K:

During the evaluation of disclosure controls and procedures as of December 31, 2007 ..., a material weakness in internal control over financial reporting relating to the fair value valuation of the AIGFP super senior credit default swap portfolio was identified. As a result of this material weakness ...,AIG's Chief Executive Officer and Chief Financial Officer concluded that, as of December 31, 2007, AIG's disclosure controls and procedures were ineffective.

AIG is actively engaged in the development and implementation of a remediation plan to address the material weakness in controls over the fair value valuation of the AIGFP super senior credit default swap portfolio and oversight thereof as of December 31, 2007. The components of this 


\section{Management and the Financial Crisis - William A. Sahlman}

remediation plan, once implemented, are intended to ensure that the key controls over the valuation process are operating effectively and are sustainable. These components include assigning dedicated and experienced resources at AIGFP with the responsibility for valuation, enhancing the technical resources at AIG over the valuation of the super senior credit default swap portfolio and strengthening corporate oversight over the valuation methodologies and processes. AIG management continues to assign the highest priority to AIG's remediation efforts in this area, with the goal of remediating this material weakness by year-end 2008.

The fact that the auditors discovered material weaknesses at AIG did not stop them from issuing an unqualified opinion as shown below:

Notwithstanding the existence of this material weakness in internal control over financial reporting relating to the fair value valuation of the AIGFP super senior credit default swap portfolio, due to the substantive alternative procedures performed and compensating controls introduced after December 31, 2007, AIG believes that the consolidated financial statements fairly present, in all material respects, AIG's consolidated financial condition as of December 31, 2007 and 2006, and consolidated results of its operations and cash flows for the years ended December 31, 2007, 2006 and 2005, in conformity with GAAP.

Auditors have not generally been able to stop very many trains wrecks in this financial crisis or perhaps even at other times. To the best of my knowledge, $99 \%$ of the financial firms that got into trouble in the past eighteen months had unqualified financial statements, including Lehman Brothers, Bear Stearns, New Century Financial, Countrywide Financial, Fannie Mae and CitiGroup. All these groups were in compliance with all aspects of Sarbanes Oxley. Auditors also gave unqualified opinions to Enron and WorldCom not long before they went down the tubes.

One final concern about the role of external bodies in assessing AIG relates to the relative quality of human capital inside AIG and that outside. Human capital markets work like all markets: individuals typically go to the employer willing to pay them a price commensurate with their experience and skill. At AIG's FPG unit, to illustrate, the average annual pay during the period from 2002 to 2006 for each employee exceeded \$1 million. We can infer that these were talented people. In contrast, the average pay of the folks at AIG's audit firm, PricewaterhouseCoopers, was probably considerably less than $\$ 1$ million. By implication, the auditors might not have been at the same talent level. It is almost always an unfair fight when a group of highly skilled professionals interacts with a group of less skilled professionals in the sense that it is hard for the latter to overrule or second-guess the former. It may also be very hard to detect clever fraud.

My assertion that the auditors were not necessarily up to the task of auditing AIG and FPG might seem harsh. Certainly, PricewaterhouseCoopers has some 


\section{Management and the Financial Crisis - William A. Sahlman}

terrific people who are great at their job. But, on average, they were tasked with auditing really smart and clever people doing complicated activities. The same can also be said of regulatory agencies like the SEC and the OTS, as well as at the ratings agencies, S\&P and Moody's: these groups had talented people but perhaps not quite as skilled as those at AIG.

Outside monitors also failed to identify the looming crisis at AIG. Consider regulators: as at many financial services firms, AIG had some discretion over the regulatory context for their decisions. Apparently, AIG's management determined that the best primary regulator for their financial business was the Office of Thrift Supervision (OTS). Again it's a complicated story. The U.S. has developed a complex patchwork quilt of regulatory bodies, each with different authority, tools and capabilities. Congress has mandated that these organizations self fund by charging fees for supervising firms. One unfortunate, but inevitable, consequence is that the agencies compete for the right to supervise those firms.

AIG's chosen regulator - the OTS - was well known for offering the lightest regulatory touch. In one famous episode, the head of the OTS brought a chainsaw to a press conference to slash through thick manuals of financial rules while his counterparts from the FDIC and the Federal Reserve brought simple but anemic scissors. ${ }^{8}$ The competitive battle between these regulators was not unlike the battle between mortgage brokers that resulted in a race to the bottom in mortgage standards. ${ }^{9}$

Beyond regulators, other external monitors might have caught looming problems at AIG earlier. Consider stock analysts: a well-respected firm like Morgan Stanley considered AIG's stock to be undervalued until shortly before the government bailout in September 2008. In reading reports on AIG from 2007 to 2008, one is struck by the degree to which problems at FPG (and AIG) were recognized after the company announced them, not before. That is, external sellside analysts did not identify FPG's exposure to subprime mortgages as a source of serious concern until it was too late. That is not surprising because analysts are highly dependent on information from the company. After Reg FD and other regulatory changes, it is hard for an analyst to get proprietary information. Also, no analyst report I have ever read really gets into detailed discussions of the nexus of incentives, controls, accounting, human capital and culture. That means they are unlikely to discover festering problems.

We have already learned that the ratings agencies downgraded AIG but the major downgrade occurred on September 15 long after management and the board might have been able to take corrective action. As a rule, ratings agencies rate using

8 Paul Kiel , "Regulators, Banks' Favorite (Toothless) Regulator,” ProPublica November 25, 2008.

${ }^{9}$ Countrywide Financial also opted to be regulated by the OTS shortly before it ran into real financial difficulties as a result of exposure to subprime mortgages. 


\section{Management and the Financial Crisis - William A. Sahlman}

a rear view mirror that limits their usefulness as part of the overall system of corporate governance.

That returns us to the basic challenge of having management teams understand risk and reward and not expose their company or the global financial system to failure. One logical question is whether any companies navigated successfully through the financial bubble by addressing these issues more effectively. Goldman Sachs seems to have been far more adept in this regard than its major competitors. At the level of culture, Goldman ${ }^{10}$ has always focused on protection of the whole company ("Mother Goldman") and has managed to avoid taking on too much risk in any sector. The company also has an internal cultural mantra of being "long term greedy," a phrase used by Gus Levy, a former chairman and legendary company builder. As a result, Goldman eschews decisions that may have high short-term payoffs at the expense of long-term payoffs.

Goldman's culture evolved during the long period the company was a private partnership with a flat ownership structure. Until 1999, when the company went public, partners received a share of the partnership that did not vary with their individual profit contribution but with the time they made partner. All the new partners in a given year received the same share of profits. Partners, by implication, cared deeply about how their particular units were performing and about how all the other units were doing. Moreover, partners received low base-level cash compensation (e.g., $\$ 100,000$ ) and could not take all their capital out of the company. There were restrictions on capital withdrawals even after retirement. The company appointed partners on a two-year cycle and had a history of removing partners who did not buy into the culture or were not performing. Goldman's strong culture survived the transition to public ownership.

Goldman is well known for having one of the best risk measurement and management systems on Wall Street, a capability that evolved when partners had joint and several liability for the firm's capital. Having one's personal balance sheet at risk while having constrained ability to withdraw capital focuses the mind on managing the relationship between risk and reward. While Goldman has certainly had periodic episodes of trading losses or even bad behavior, the magnitude of these exposures has always been modest relative to the firm's capital.

One example of a Goldman risk measurement and management strategy concerns pricing of trading positions. As noted earlier, all companies engaged in trading activities have to be concerned with trader behavior. At Goldman, there is a parallel organization to the trading group that is charged with pricing trading positions, limiting excessive concentration, and managing risk. That group has people with comparable skill, stature and compensation. The group is populated with former traders - they know all the tricks. They can question any price or

${ }^{10}$ For additional information on Goldman Sachs, see Charles. D. Ellis, The Partnership: The Making of Goldman Sachs, Penguin Group, 2008. 


\section{Management and the Financial Crisis - William A. Sahlman}

decision. If they think a price is stale or wrong, they force the trader to sell part of the position to have the market verify the price.

Goldman managed to survive the financial panic that began in the fall of 2008. They had correctly determined that there was substantial risk in housing related securities. They were often on the other side of trades with AIG's FPG, buying insurance against a default in mortgage-backed securities. They even found ways to hedge their exposure to AIG. Yes, Goldman did receive money from the U.S. government (subsequently repaid) and they were forced to convert to a bank holding company status at the peak of the crisis. Having said that, the company has thrived as the financial markets have firmed back up. By having avoided the crisis in the first place, Goldman was able to take advantage of the weakness of competitors and has piled up record profits.

Goldman was not the only firm to survive the near-cataclysmic events in the fall of 2008. JP Morgan Chase also navigated successfully through the crisis. Jamie Dimon, JP Morgan Chase's Chairman and CEO, anticipated the crisis, though not its depth. He emphasized in his annual reports to shareholders in 2005, 2006, 2007 and 2008 the importance of having a "fortress balance sheet" and of managing risks. He withdrew from the subprime mortgage business in 2005 and avoided the general area of Structured Investment Vehicles that combined illiquid risky, medium and long-term assets with lots of short-term leverage. When Dimon first became CEO of the company in 2005 , he focused in his report to shareholders on the importance of recognizing and managing risks:

Almost all of our businesses are risk-taking businesses - and we spend a great deal of time thinking about all aspects and types of risk inherent in them, including:

- Consumer and wholesale credit risk

- Market and trading risk

- Interest rate and liquidity risk

- Reputation and legal risk

- Operational and catastrophic risk

The notable fact about the first three risk areas is that they are cyclical, and all of them have elements of unpredictability. This requires us to be prepared for inevitable cycles. A company that properly manages itself in bad times is often the winner. For us, sustaining our strength is a strategic imperative. If we are strong during tough times - when others are weak then the opportunities can be limitless. Protecting the company is paramount.

Dimon would be the first to admit that JPMorgan Chase made mistakes while he was CEO, but he and his team positioned the company to ride out the storm and even prosper because of their relative financial strength. They were able to buy 


\section{Management and the Financial Crisis - William A. Sahlman}

Bear Stearns and WaMu (Washington Mutual) at fire sale prices when those companies collapsed in the depths of the panic.

At any point in history, there are obvious winners and losers. It is not easy to say exactly why any group succeeds - it could just be luck that differentiates two groups. I think, however, that firms like JP Morgan Chase and Goldman Sachs truly had superior people, systems, and, most importantly, culture, which enabled them to outperform their compatriots.

\section{The Big Picture}

Modern economies have complex systems of checks and balances that guard against bad behavior and excessive risk. By all measures, those systems work pretty effectively, as evidenced by long-term growth in the global economy and infrequent corporate meltdowns. But, these systems are not perfect, and they failed miserably in the period leading up to the financial crisis.

I have argued that the macroeconomic mess we are in was the result of a series of misguided microeconomic decisions made by many managerial actors in the private and public sector across most geographic boundaries. I attribute the crisis to an unfortunate concurrence of uncoordinated but widespread incompetence.

To understand what has happened and what we should do to keep it from happening again requires helicoptering up to see the broader factors that created the context in which mass incompetence could occur and be sustained. The first and most important fact about the global economy leading up to the crisis was that there had been an explosion in global liquidity. According to a study by McKinsey, global financial assets doubled from 2000 to 2007, from $\$ 94$ trillion to almost $\$ 200$ trillion. ${ }^{11}$ This makes sense because of the rapid growth and high savings rates in countries like Brazil, China, India, and Russia. The Middle East was also accumulating wealth because of increased demand and pricing for oil.

Think of an unfettered $\$ 200$ trillion trying to find a home. Almost all barriers to cross-border investing have been eliminated. Information has been completely democratized by the Internet and by information services like Bloomberg. As a result, money moves quickly in response to perceived opportunity, driving up prices, lowering expected returns, but increasing past returns. And, because capital almost always moves faster than real opportunity, imbalances occur frequently.

That amount of capital searching for returns also encourages financial innovation. Wall Street types are constantly creating new instruments that promise high return and low risk to attract investors. This process can lead to terrific

11 McKinsey Global Institute, Mapping global capital markets: Fifth annual report, October 2008. 


\section{Management and the Financial Crisis - William A. Sahlman}

innovations that have broad and enduring benefits but it can also lead to the opposite. Unfortunately, any good idea can and will be taken to its illogical conclusion. That certainly was the case in areas like securitization and auction-rate securities.

Boom times are also often accompanied by loosening regulation. In some cases, regulators specifically chose not to regulate new securities like credit default swaps. In other cases, regulators allowed a blurring of the distinction between different financial intermediaries. The prime example was the dismantling of Glass Steagall, an act that had separated investment banking and banking. And, because boom times mask risks, regulators allow increased leverage, as occurred when the Securities and Exchange Commission specifically allowed securities firms to set their own leverage ratios.

Warren Buffett famously remarked that you only find out who is swimming naked when the tide goes out. By implication, when the tide is in, there is an increase in the incidence of naked swimming. In less graphic terms, lots of bad behavior occurs in rising markets. At one end of the spectrum, one observes massive frauds as occurred with Bernie Madoff and Allen Stanford. At the other end, you see risky business decisions as occurred at scores of financial services firms.

In contrast to general positive economic trends around the globe in the period leading up to the crisis, there were significant challenges in the U.S. Basically, this country was in difficult financial shape along a number of dimensions:

- Slow growth in real personal income

- Zero savings rates in the personal sector

- Large structural deficits in the Federal budget

- Increased leverage at all levels - personal, corporate and government

Though the U.S. economy faced considerable challenges, there was absolutely no evidence of that in our financial markets. Financial markets boomed, with rising prices, increased volume and few warning clouds on the horizon. Moreover, there was a massive increase in the level of speculative synthetic assets. Analysts often point to the $\$ 60$ trillion in credit default swaps outstanding at the end of 2007 , but that number pales in comparison to the almost $\$ 800$ trillion total derivative securities available at that time.

This was a great time to be in financial services particularly in the U.S. Profits boomed, compensation boomed, and everyone did well. To illustrate, between 2002 and 2007, annual revenues at Goldman Sachs went from \$355 billion to $\$ 1.12$ trillion while operating profits went from $\$ 3.2$ billion to $\$ 17.6$ billion. Over the same period, revenues at Lehman Brothers went from $\$ 6.1$ billion to $\$ 19.3$ billion while operating profits went from $\$ 1.5$ billion to $\$ 6.3$ billion. By 2007 , profits 


\section{Management and the Financial Crisis - William A. Sahlman}

of financial firms in the S\&P 500 represented 31\% of total profits for all companies in that index.

It is not surprising that every manager at firms active in the financial markets was eager to see the boom continue. More broadly, everyone appeared to benefit from the ebullient conditions in the capital markets. Homeowners could unlock value in their houses by refinancing at low rates or taking out home equity loans. New homebuyers could enter the market with remarkably generous terms. Companies could borrow massive amounts at very low absolute and relative rates. Universities could increase spending as endowments soared. Politicians could take credit for growth in the economy and for increased rates of homeownership.

That is the nature of bubbles. Human beings seem ill equipped to see building risks. The dominant form of forecasting seems to be linear extrapolation, or worse, log-linear extrapolation. People want tomorrow to be better than yesterday. There is no constituency for bursting bubbles.

Looking back at the so-called Internet bubble, to illustrate, one sees remarkable consistency in behavior. In 1999 and early 2000, everyone involved in the high tech sector of the economy was prospering. Quite a few pundits noted that the valuations assigned to dotcoms were ridiculously high but that didn't stop investors from piling into such stocks.

The only distinction between the Internet bubble that ended in 2000 and the credit bubble that ended in 2007 and 2008 was the degree of collateral damage. When the earlier bubble burst, stocks went down, investors who had bet heavily on the sector lost money, but the impact on the domestic and global economy was modest. Indeed, some of the excessive investment benefited the economy in the long run. Sadly, that was not the case with the credit bubble, which brought the global financial system to the brink of total collapse.

The broader context for the recent financial crisis is important because that context will be repeated again and again. That is, there is still massive wealth in the world that will forever move quickly across all national boundaries. That wealth also means that domestic regulatory efforts are doomed because global regulatory arbitrage will circumvent any chauvinistic plan.

Moreover, bubbles are part of our basic economic system. They have always existed and there is no way to eliminate them. Therefore, any recommendations for management must take into account that each day we are one day closer to the next bubble.

If bubbles are here to stay, so too are panics. All modern financial systems are built on trust and confidence. When trust and confidence are rocked, panic ensues. When the financial system came close to imploding in the fall of 2008 , the actual financial risks to which the economy was exposed were manageable. That is, 


\section{Management and the Financial Crisis - William A. Sahlman}

a global economy with over $\$ 200$ trillion in financial assets can sustain losses, even large losses. If the total exposure around the world to subprime mortgages - the worst of the loans that had been made - was several trillion dollars, that amount could have been absorbed. Lots of investors would have lost money but the system should not have collapsed.

What really caused the financial meltdown was uncertainty about the size of the losses and the interconnected risks caused by derivative securities. Everyone became risk averse simultaneously, everyone worried about everyone else, and everyone panicked. That panic inflicted far greater losses than the core losses that would have been caused by profligate lending.

I don't believe that any new regulations, even globally coordinated, competently crafted ones, will eliminate the possibility of bubbles or panics. Trust and confidence are ultimately ephemeral. Even economically small events, like the meltdown in 1998 of Long-Term Capital Management, can set off financial distress. Therefore, managers need to prepare for a world in which trust and confidence can collapse and in which animal spirits can run amok.

\section{What to Do?}

It seems to me that most of our attention should be focused on the first line of defense against microeconomic mistakes that might lead to macroeconomic meltdowns - company management. Management, including the board of directors, at companies like AIG should have been aware of the risks to which they were exposing their companies independent of the role of external monitors. Management should have been more alert to the existence of a financial bubble.

At one level, the recommendations for improving management are almost trivial. Surely, no home lender should ever lend $100 \%$ of the inflated value of a house based on hope and no documentation. No lender should lend billions to companies purchased in buyouts at inflated values with high leverage and no covenants. No ratings agency should assume that house prices cannot decline or that prices in different regions are uncorrelated.

It also seems patently obvious that no management should ever leverage their company at 30 to 1 , unless of course they have found a riskless asset whose continuous, guaranteed return exceeds the locked-in cost and guaranteed-to-beavailable borrowing for the transaction. If they think they have found such a combination, they should also look for a perpetual motion machine.

Consider the arrogance inherent in Lehman Brother's (or Bear Stearns') 2007 leverage of over 30 times (Total Assets to Shareholders' Equity). That ratio exceeded 50 times in between reporting periods. If you think about it, a small decline in asset values wipes out equity. Moreover, when a company like Lehman or 


\section{Management and the Financial Crisis - William A. Sahlman}

Bear Stearns borrows in the short-term financial markets, they can find themselves cut off from credit exactly when asset values are under pressure.

In reading about the final days of Bear Stearns and Lehman Brothers ${ }^{12}$ one is struck by how senior managers at both firms failed to understand the degree to which they were exposed right up until days before they collapsed. At Bear Stearns, to illustrate, the company had massive exposure to mortgage-backed securities. Even as the housing market toppled with rising default rates and lower house prices, Bear Stearns did not materially change its business or financing.

When Bear Stearns got in real trouble in early 2008, every part of its business began to shrink. The company had a large and successful prime brokerage business that serviced investment management firms and hedge funds. As rumors spread about Bear Stearns, clients started to withdraw their funds at a rapid clip, which drained Bear Stearns' cash reserves. At the very same time, access to the overnight financial markets became more difficult. Investors either refused to do business with Bear Stearns or demanded more collateral for loans. Bear Stearns reached the point at which they could not survive the run on the bank that was precipitated by concern about its viability.

All of the firms in financial services had what I call "hidden leverage" that is not captured in their apparent asset to liability ratio. At AIG, the company had businesses that originated subprime mortgages, businesses that insured individual loans, and a major business providing credit default swaps on pools of subprime mortgages. The company also had a major potential shift in financial health if counterparties demanded more collateral in response to a lower corporate rating. That is precisely what occurred - asset values and income shrank while liabilities rose. To see this hidden leverage would have required a detailed analysis of all the footnotes to the financial statements, not just the numbers as presented. ${ }^{13}$

Similarly, at CitiGroup, Merrill Lynch and Bear Stearns, there were offbalance sheet activities that came back to haunt the firms. I have already mentioned SPEs and SIVs. These vehicles provided extra income but ended up being toxic when short-term capital markets froze. At Bear Stearns, the firm had started two hedge funds that invested in mortgage-related securities. Bear Stearns had significant liabilities when these two funds failed.

I define leverage as the likelihood and consequences of losing control of your operations as a result of bearing risk. Bear Stearns and Lehman Brothers had high

12 See, for example, William D. Cohan, House of Cards: A Tale of Hubris and Wretched Excess on Wall Street, Doubleday Publishing, 2009 or Gillian Tett, Fool's Gold: How the Bold Dream of a Small Tribe at J.P. Morgan Was Corrupted by Wall Street Greed and Unleashed a Catastrophe, Free Press, 2009.

13 Even with hindsight, it is difficult to ferret out the real risk exposure at any large, global financial services firm. 


\section{Management and the Financial Crisis - William A. Sahlman}

reported financial leverage and even higher hidden leverage. These were tightly wound organizations that were vulnerable to changes in asset and liability markets. Both firms did not need to fail. Both firms had strong franchises and competent people. Both firms could have taken steps to avoid getting caught in a death spiral. These firms were not killed; they committed suicide.

Many observers of the financial crisis have discussed the concept of the "black swan," a rare event that in financial markets can wreak havoc. I am not convinced that anything that happened in 2007-2008 was particularly surprising or rare. To illustrate, in 1998, a group of financial whizzes were running a successful hedge fund called Long Term Capital Management (LTCM). ${ }^{14}$ They levered their assets at something like 30 to 1 . They had assessed that there was effectively no chance that their assets could drop in value by as much as even $3 \%$. They had locked in a riskless arbitrage return. Sadly for them, there were some unanticipated events in the capital markets - problems in Russian financial markets - that caused their hedges to go the wrong direction. For a period of time, the correlation coefficient on all assets went to 1.0000. All asset classes went down simultaneously and the spreads between prices of similar assets widened; long-term riskless arbitrage became risky in the short term. LTCM had high financial leverage and lost control when financial markets melted down, spreads went against them, and funding sources evaporated. Their bets probably would have paid off in the long run but they did not get past the short run.

What happened with LTCM in 1998 happened again to the entire global financial market in 2008. If you think about the $\$ 200$ trillion racing around the world at the beginning of the most recent crisis, you can see how prices might all go down simultaneously. As soon as people began to understand how far out on the limb they were, they ran for the exits. I equate this to someone yelling fire in a crowded theater in which some of the doors were locked. That is, many hedge funds and other alternative investment categories had gates that precluding divesting quickly. The presence of gates in one part of the financial markets meant people had to go to other places to get liquidity, which caused indiscriminate dumping of all assets on a global basis. The only distinction between prior financial crises like the one surrounding LTCM and the more recent one was a matter of violence, size and duration, not underlying forces.

The managerial point is simple: don't have excessive leverage and plan for financial market disruptions. That is not a new maxim for effective management. In 1969, one of my colleagues, Gordon Donaldson, published a book entitled "Strategy for Financial Mobility." He defined financial mobility as "the ability to adjust the magnitude and timing of corporate funds flows in response to unexpected events (opportunity or adversity) and thus to assure solvency and continuity." Jamie

${ }^{14}$ See Andre Perold, Long-Term Capital Management, L.P. (A) 9-200-007, revised 11/5/1999, (B) 9-200-008 10/27/1999, (C) 9-200-009 10/27/1999, and (D) 9-200010 10/27/1999, Harvard Business Publishing. 


\section{Management and the Financial Crisis - William A. Sahlman}

Dimon at JPMorgan Chase pursued a strategy for financial mobility by limiting the company's vulnerability to a market disruption and preserving the option to buy assets at distressed prices. In contrast, Bear Stearns, Lehman Brothers and many other financial firms sacrificed financial mobility for greater short-term profits. They borrowed short to invest long, they relied on "hot" overnight funding, they had high debt relative to equity, they had limited cash liquidity (relative to the cash required in a panic), and they all responded too late to the crisis.

Though I have focused on the management of financial services firms, the same lesson applies to all firms. Consider all the industrial companies that were dependent on short-term bank lending or commercial paper markets. As the crisis unfolded in the fall of 2008, commercial paper markets froze and many banks became cautious. Though quite a few firms drew down their maximum line of credit, other firms were vulnerable to being cut off from short-term financing. Many firms that were performing well even as the recession began in earnest became insolvent because of problems at their own lender or general problems in the financial markets. Still other firms recognized the possibility of financial market volatility.

To illustrate, Richard Reese, Chairman of Iron Mountain, an information storage and protection company, decided in the summer of 2008 that financial markets seemed problematic and he implemented a plan to replace some of his short-term debt with long-term debt and increase cash on the balance sheet. As the crisis developed in September, he drew down $\$ 150$ million of his revolving line of credit to make sure he could finance his business without disruption. These decisions are described in the following section of Iron Mountain's 2008 10-K:

During 2008, the stability of the global financial system came into question. Several banks, some of them members of our syndicated revolving credit facility, went bankrupt or were forced to merge with stronger institutions. Banks stopped lending to each other, thereby freezing credit globally. In September 2008, in response to this global credit crisis, we elected to increase our borrowings under our revolving credit facility by $\$ 150.0$ million to ensure access to these funds. We subsequently repaid $\$ 100.0$ million of these borrowings in the fourth quarter. As of December 31, 2008, we had sufficient cash on hand to repay all of the borrowings outstanding under our revolving credit facility, which is supported by a group of 24 banks and/or financial institutions.

Richard Reese's deliberate moves to make sure his company could operate in a difficult financial market were particularly important because the company has historically been fairly highly leveraged. The company has reasonably stable operating cash flows but would have been vulnerable to a liquidity crisis if denied access to bank credit. 


\section{Management and the Financial Crisis - William A. Sahlman}

Surely, preserving financial flexibility is going to be an ongoing priority for everyone from company managers to investors. The perceived value of such flexibility is, however, as volatile as the financial markets. Unfortunately, most actors do the opposite of what they should do - they sacrifice financial flexibility during boom times and do the opposite during crises. That pro-cyclical behavior is precisely what exacerbates the negative impact of panics.

Beyond the dangers of excessive leverage - or impaired financial mobility there are more pernicious challenges for managers that were laid bare by the crisis. Problems always arise inside companies, I believe, because of fundamental flaws in culture, incentives, risk measurement, controls, accounting and human capital. Therefore, we need to understand these systems and improve them. Consider the following sequence of questions:

- What are the implicit and explicit incentives within the organization?

- How will individuals and groups behave in their own perceived best interest?

- Are the incentives and organizational objectives aligned?

- What behavior should be encouraged? Discouraged?

- Where is bad behavior most likely to occur and under what circumstances?

- To what degree do contextual factors (economy, competition, etc.) change incentives?

- Is there alignment with respect to the appropriate time horizon for meeting objectives and measuring performance?

- Does the company accurately measure and report economic profits and losses?

- Are the "right" people attracted and retained by the organization?

- Are the "right" customers attracted and retained by the organization?

- Given the incentives and people involved, what measurement and control systems must be in place?

- What is the company culture and how does it exacerbate or ameliorate issues in incentives and controls?

- What is the relative quality and status of people responsible for generating profits and people responsible for measuring profitability and controlling risks?

- Who has responsibility for managing culture, human capital, incentives, controls and accounting within the organization?

These high level questions should have been posed and addressed at each and every firm described in this article. At UBS and AIG, to illustrate, there was a near fatal combination of strong personal incentives, inadequate measurement and control of risk, bad accounting (as chosen by the people with the incentives), the wrong people and a culture that ultimately did not protect the company. At Goldman Sachs and JPMorgan Chase, there were strong incentives balanced by a 


\section{Management and the Financial Crisis - William A. Sahlman}

conservative culture, sound risk measurement and management and conservative accounting.

These questions would have been useful in previous financial or governance crises. For example, the board of directors at Enron allowed the CFO, Andrew Fastow, to set up a separate partnership to buy assets from Enron in order to move those assets off Enron's balance sheet. Fastow, as it turned out, was allowed to be the General Partner of the partnership, which meant he was in the enviable position of negotiating with himself. It doesn't take a rocket scientist to realize that there might be a conflict of interest in this structure. Fastow was also in charge of setting the accounting treatment for the transaction, which, not surprisingly, increased reported profits and decreased leverage for Enron. The point is simple: bad things happen when incentive systems are perverse, controls inadequate, people with clear conflicts set accounting policy, and the people involved are ethically challenged.

The concept of auditing an organization to assess incentives, controls, measurements, human capital and culture is universally applicable. That is, the questions posed above are as helpful to understanding and managing government agencies or other political bodies as they are to understanding and managing financial service firms. Moreover, I think a primary responsibility of regulators is to understand the underlying issues at firms they regulate and how those issues play out at the industry level.

Regulators deserve some blame for the financial crisis because they failed to understand how individual and company incentives might drive behavior and increase systemic risk. The simplest example of a problem relates to moral hazard, the possibility of bad behavior by insured parties. There are so many examples of moral hazard leading up to the crisis that it is hard to know where to start. The most costly example relates to the GSEs, Fannie Mae and Freddie Mac. The government was on the hook if their financial decisions turned out to be poor, but the executives and shareholders had much to gain if risky bets paid off. Indeed, some elected government officials actually encouraged these firms to make risky bets because they believed these bets were in the best interests of their constituents.

As noted earlier, a critical flaw in government policy was its unwillingness, or political inability, to charge Fannie Mae and Freddie Mac an insurance premium commensurate with the risk the government incurred because of its implicit guarantee of their liabilities. At the company level, that same mistake is repeated time and time again when companies fail to charge a capital cost commensurate with the riskiness of the assets purchased with the capital. UBS and AIG acknowledged precisely that issue by noting that they charged a low cost of capital that encouraged risky investment decisions, benefiting the individuals involved in the short-term but exposing each company to risk of ruin. 


\section{Management and the Financial Crisis - William A. Sahlman}

For regulators and policy makers, the challenge is clearly magnified because of the ways in which bad micro-level decisions can cascade into macroeconomic disasters. For example, the subprime mortgage troubles can be traced directly to the individual decisions of borrowers and mortgage brokers. Individuals, who made a current fee and had no liability if a loan went bad, channeled money to individuals who couldn't afford to borrow. The race to the bottom in lending standards that occurred in mortgage (and other) markets is a predictable outcome of the confluence of strong incentives, weak controls, bad accounting, inadequate human capital, and dangerous cultures at individual firms and across the entire housing industry.

If I am correct in my belief that the underlying problems are complicated and interconnected within organizations and across them, then current government efforts to address issues seem doomed. For example, some in government have proposed limits on a firm's ability to use asymmetric payoff structures in compensation. These structures typically involve big bonuses if a deal does well but no real clawbacks or penalties if the deal later fails.

But, the real problem isn't payoff structures per se. Many prudent, high performance firms have such compensation systems but they also have the right control systems, the right accounting measures, skilled and high-integrity people, and constructive cultures. Unless government regulators are willing to work at such a system level, they will not succeed in ameliorating the issues that underpinned the financial crisis. Previous attempts to fix one part of the problem - for example, improving audit quality and independence as addressed in Sarbanes-Oxley - have failed to prevent even more serious problems. Moreover, it's ludicrous to imagine government could ever come up with regulations comprehensive enough to protect against systemic risk while allowing the economy to function.

One possible approach that might be useful would be to foster the creation of a new kind of external monitor of corporate health and balance, one that could provide helpful insight and advice to managers and regulators. Such a monitor would look at an organization like CitiGroup from a holistic perspective. They would do a deep dive into incentives, controls and measurement, accounting, human capital and culture. They would identify key risk areas and core underlying assumptions in and across all business units and across all geographic boundaries. They would identify strengths and weaknesses. They would report first to a committee comprising independent directors and then to management and the whole board. The new monitor might even assess appropriate fees for regulators to charge, given the inherent risks at the company, and the implicit or explicit existence of a government guarantee.

There are many challenges associated with creating a new kind of monitor. The first and most obvious is how to attract the right caliber people to the team. If the people are materially less capable than those running the company, the process will be ineffective. The second issue is deciding who pays for the service and how 


\section{Management and the Financial Crisis - William A. Sahlman}

much. I believe the fees should be high for systemically risky companies and that those companies should pay. Because great people are needed in such a new firm, individual compensation should be high and probably based in part on a retrospective assessment of the quality of the analysis. The new monitor should not be a government entity, per se. The board of the new firm should comprise outstanding executives and economists. ${ }^{15}$

There were quite a few people who correctly saw the credit bubble coming (and going) and who understood weaknesses at specific companies. These are the kinds of people you would like to have assessing the major financial firms whose managerial failures exposed the global financial system to overwhelming risks and whose assets and liabilities are effectively guaranteed by the government because they are too big to fail.

From a broader perspective, the idea that a new kind of monitor is required should be obvious from the discussion to this point. We have seen that the current system is too fractured to be effective. Individual regulators have responsibility for subsets of the activities of the firms under their purview. No external body ever looks at compensation except the auditors who only assess whether the pay was correct according to the formula. No one assesses the core assumptions about risk at the entire firm. No one relates risk measures - like Value at Risk (VAR) - to the people making the underlying decisions. No one ever looks hard at culture. No one ever looks at who makes accounting decisions and how they are paid. No external body has human capital that matches that inside the firms being regulated.

The problem confronting those responsible for the financial health of the country is the same problem as in healthcare. Effectively, we have created a system in the U.S. that rewards the quantity of healthcare, not the quality of health delivered at a given price. We have atomized oversight and have few examples of organizations that take a holistic, system-wide approach to patients. What I am calling for is a Mayo Clinic for large financial services firms with the distinction that the new clinic makes house calls.

If I were a director of a firm like AIG or General Electric, I would insist that such a new monitor make an independent evaluation of my firm. I would likely propose that the audit committee and the compensation committees be disbanded in their current form. I would charge the whole board with understanding and monitoring corporate culture, human capital, accounting policies, control and measurement systems, and incentive compensation. I would emphasize the overall assessment of risk and reward, including developing a strategy for financial mobility. Because of the complexity of the tasks I believe boards would need

15 Given the old saw that it takes a thief to catch a thief, it might make sense to get input from people who had previously gamed the system before getting caught. Someone like Bernie Madoff might have useful insights for boards, investors and regulators. 


\section{Management and the Financial Crisis - William A. Sahlman}

outside help to be effective. To rely only on management or on focused groups like auditors would be misguided and dangerous.

The severity of the global financial crisis has no doubt instilled everyone with a new conservatism. All players will be more diligent, ask tougher questions, and pull back on risks. That was true after the financial scandals associated with Enron and WorldCom. Temporary surges in piecemeal scrutiny and conservatism do not, however, constitute solutions to complex problems.

I cannot overemphasize how complex the key issues are at the core of financial crisis and how difficult it will be to make real progress. Take a domain like compensation. There are no perfect compensation systems. We can certainly look at the past few years and assert that option-like payoff structures - large upside, limited risk - have been problematic. But, what is the alternative? The opposite approach - limited upside, large risk - might not attract or motivate the right people. Moreover, compensation policies are determined in part by market forces. If one firm decided to force employees to be subject to longer-term risks (e.g., forcing mortgage officers to defer pay until a mortgage is paid off), another firm might offer a more compelling package without the long-term liability.

We have also seen that requiring that a significant portion of compensation be in the form of stock (restricted or not) made little difference in deterring the risky managerial decisions that plagued the financial markets. Many executives with major stock positions made bad decisions and suffered massive hits to their net worth.

Even outside the firm, compensation is complicated. For example, should the issuers or the investors pay ratings agencies? If issuers pay, ratings might not be objective as agencies compete for the business. If investors pay, ratings might be biased down. Or, if government pays, the quality of the people involved might not be as high as it would be in a private institution. And, of course, the notion that ratings can be assigned to a security independent of the people and systems behind the security is suspect in the first place. For evidence, see the ratings applied to bundles of subprime mortgages assembled by firms like New Century Financial.

Or, consider the broader issue of compensation and recruitment in the government. An agency like the Securities \& Exchange Commission has a staff that includes career veterans and hundreds of young recruits from law schools. The government pays the latter group modest pay, but the group benefits from the experience when they take jobs at traditional law firms. Turnover is high. The SEC faces an almost impossible task considering the enormity of its scope, the complexity of the economic and regulatory issues, and the relative inexperience of most of the staff. Total financial assets in the U.S. exceed $\$ 100$ trillion, even after the crash. Total employment at the SEC is under 6,000. 


\section{Management and the Financial Crisis - William A. Sahlman}

In a recent assessment by the Office of the Inspector General of why the SEC failed to catch Ponzi-schemer Bernard Madoff, the SEC acknowledged the relative inexperience of its staff:

According to the examiner, at the time of the Madoff examination, OCIE (an investigative unit of the SEC) "didn't have many experienced people at all," noting that "we were expanding rapidly and had a lot of inexperienced people conducting examinations." Another OCIE examiner stated that "there was no training," that "this was a trial by fire kind of job" and there were a lot of examiners who "weren't familiar with securities law." The team was composed entirely of attorneys .......16

In higher levels of government, the various systems (incentives, culture, accounting, etc.) may be as challenged as in the private sector. For example, politicians receive low cash compensation but have extraordinary intangible payoffs. As evidenced by intellectually and economically corrupt government accounting, massive leverage, miserable forecasting ability, limited accountability, and weak rule-making, it is not at all clear that the political system works in terms of managing the financial affairs of the country. Should we tie compensation of our politicians to metrics like financial health, risks, predictability, and/or long-term quality of legislation (including assessments of unintended consequences)? Though Washington has been quick to criticize the corporate sector, it is not obvious that there has been much self-reflection or that the pot is not calling the kettle black.

If a new external monitor for corporations would be useful, a similar body for government policy might be as impactful. For example, wouldn't it be a good idea to try to assess the inherent incentive effects of any new regulation. How will private and public actors behave in response to shifting rules? How will incentives change over time? What control systems are required? Again, these are questions to which the FDIC, the Federal Reserve, the U.S. Congress, and the President should have sought answers.

Though the questions are obvious, the answers will be hard to find. Frankly, our knowledge about how complex global economies and financial systems work at all levels is primitive. It has been interesting to see academics try to understand the financial crisis. There have been fabulous new articles about why, for example, ratings on mortgage-backed securities were flawed. These articles might have been more useful before the crisis rather than after. Academics have also poked holes in various widely accepted measures like Value-at-Risk. Again, a little foresight would have been helpful.

16 REPORT OF INVESTIGATION, UNITED STATES SECURITIES AND EXCHANGE COMMISSION OFFICE OF INSPECTOR GENERAL, Case No. OIG-509, Investigation of Failure of the SEC To Uncover Bernard Madoff's Ponzi Scheme, 9/3/2009, pg. 10. 


\section{Management and the Financial Crisis - William A. Sahlman}

\section{Summary and Conclusions}

We have spent the past year mired in a global financial crisis that few saw coming and that will plague us for years to come. Such crises are gut wrenching. Collectively and individually, we search for causes and solutions. That process is healthy, normal and dangerous. Too often, we look for quick fixes that do long-term damage or we put the equivalent of duct tape on obvious problems, missing the true root causes.

I have argued in this article that the macroeconomic problems were the result of terrible microeconomic decisions. Executives at a stunning array of financial services firms put themselves, their companies, their employees, their customers, and their communities at risk. It was as though some overwhelming anti-common sense virus swept through Wall Street and other financial capitals around the world.

I believe that the root cause of bad decision-making resides in the nexus of culture, incentives, control and measurement, accounting and human capital. When those elements are aligned, good things happen and bad things don't happen. When they are out of alignment, particularly in competitive industries, really bad things happen.

Outside agencies - regulators, securities analysts, ratings agencies, auditors, news media, investors, politicians, and regulators - did not prevent the crisis. Nor did boards of directors. While there are many ways to improve how outside agencies function in our system of corporate governance, I doubt any changes will prevent future crises.

Take a simple example of a positive improvement in regulatory policy that would involve imposing higher permanent capital minimums on systemically important financial firms. Those requirements might even be contra-cyclical higher reserves required when asset prices are high and lower when times are tough. Increasing the buffer between an implicit Federal guarantee and private responsibility is a good idea - it may lower the likelihood of a panic and of forcing the government to step in. History reveals, however, that increasing the buffer will not stop clever people from figuring out ways to bypass regulated structures and, in the end, put the system back at risk. The rules and regulations become a point of departure for finding unfettered ways to make money and use leverage.

Therefore, most of the attention has to be placed on management. That is why we need a new kind of comprehensive analysis monitor. That new entity would take an objective, hard-nosed look at major financial services firms on a holistic basis. They need to understand and assess the microeconomic determinants of systemic financial risk. Their analysis needs to feed into regulatory decisions. 


\section{Management and the Financial Crisis - William A. Sahlman}

A new monitor would learn from working with many players in an industry. Auditing the best and worst firms would create powerful tools for improving practice. I don't believe current boards of directors have much hope of playing a truly constructive role because they are not sufficiently trained, they don't spend enough time, and they have little basis for comparison between best and worst practice. Working with a new highly skilled, highly experienced group would enable directors to spend more time to work on other key issues ranging from strategy to human capital management.

Beyond introducing a new player to the broad system of corporate governance, I believe that business leaders need to take more responsibility for decisions. They need to do a better job of protecting their constituencies. To do so will require looking hard at risk and reward. They need to build and maintain constructive, protective cultures; sensible incentive, control, measurement and accounting systems; and, they need to hire skilled individuals of high integrity.

Imagine that you were the CEO of a financial services firm in 2007 or 2008. The right decision would have been to cut back on risk, not reach aggressively for growth. Veering away from the pack is the hardest decision for a management team to make. In the short-run, no one is happy. The sales force is furious. The company loses market share. Aggressive people abandon ship for more aggressive competitors. Profits decline on a relative basis. The stock price goes down. The "investment" in de-risking a company may ultimately pay off, though the CEO and board may have been run out of town by disgruntled shareholders.

Isn't that the essence of leadership? Leaders make tough decisions about what to do and what not to do. They sell their views internally and externally. They cannot allow lemming-like behavior. They cannot take comfort in the contemporaneous demise of everyone in an industry. They need to hold their actions to an absolute standard rather than a relative one. They have a higher responsibility.

Business leaders have been justifiably criticized for bad decisions. Unfortunately, most of the people doing the criticism are equally flawed and complicit in the mess plaguing the global economy. We have a unique opportunity to force a review of all the players in the financial system, from individual consumers to politicians and regulators to management teams at financial services firms. The root causes of the bad decisions made in each are similar. By implication, addressing only shortcomings in the corporate sector will not eliminate the problem. But that is another story. 